\title{
Ecological and economic aspects of optimizing the creation and functioning of drainage systems in accordance with modern requirements
}

\author{
Anatoly Rokochinskiy ${ }^{1}$, Yuri Mazhayskiy ${ }^{2}$, Pavlo Volk ${ }^{1}$, Roman Koptyuk ${ }^{1}$, Lubov Volk ${ }^{1}$, \\ and Olga Chernikova ${ }^{3, *}$ \\ ${ }^{1}$ National University of Water and Environmental Engineering, Soborna street 11, UA33028 Rivne \\ City, Ukraine \\ ${ }^{2}$ All-Russian Research Institute of Hydrotechnics and Melioration Named after A.N. Kostyakova, \\ Bolshaya akademicheskaya street 44/ 2, RU127550 Moscow, Russia \\ ${ }^{3}$ Academy of law management of the federal penal service of Russia, Sennaya street 1, RU390036 \\ Ryazan, Russia
}

\begin{abstract}
Land reclamation is important in the development of agricultural production for unfavorable climatic conditions. This necessitates the improvement of scientific and methodological approaches to the creation and operation of water management and reclamation facilities, including drainage systems, which are adapted to these changes. Approaches to the type and design of drainage systems based on a combination of a modern progressive optimization approach with the traditional water balance method, hydrodynamic and hydraulic methods are presented. Approaches to the systemic optimization of technological and design solutions for the creation and operation of drainage systems have been determined. It seems that the drainage system is a complex natural and technical ecological and economic system. Finding the general optimum in such a system based on the system optimization consists in substantiating local optima for all its main components of heterogeneous elements in the system effect - mode - technology - design in their interconnection. The practical implementation of a complex of predictivesimulation and optimization calculations in projects for new construction, reconstruction and modernization of drainage systems based on the developed scientific, methodological, information and software can be carried out using the appropriate toolkit, which is CAD and modern BIM technologies. The transition to optimization methods will improve the feasibility and overall technical, technological, environmental and economic efficiency of the creation and operation of water management and reclamation facilities in accordance with modern requirements.
\end{abstract}

*Corresponding author: chernikova_olga@inbox.ru 


\section{Introduction}

In modern conditions, a significant amount of agricultural products in order to improve food security is grown on lands with a regulated water regime using various types and designs of reclamation systems (RS). The aggravation of the greatest challenges of our time concerning the energy, food and water crises under the influence of changes in climatic and anthropogenic factors both at the planetary and regional levels necessitates further improvement of scientific and methodological approaches to the creation and operation of water management and reclamation facilities that are adapted to these changes, including for drainage systems (DS) in the drainage reclamation zone based on an assessment of their overall efficiency in compliance with modern economic and environmental requirements [1].

Thus, according to a generalized assessment [2], it was determined that the development of reclamation in the world in general and in the drainage zone of the Polesie region in particular is characterized by all general objectively determined, both positive and negative trends. First of all, this concerns the fact that the large-scale development of land reclamation is associated with significant capital investments, very tangible for the economy of any country, but the resulting effect is, at best, $60 \ldots 70 \%$ of the planning one. The failure to achieve the planning efficiency of land reclamation was explained by the lack of our knowledge about the results of the interaction of human land reclamation with natural processes and their consideration in the design of the RS.

Therefore, in the design and operation of RS, including DS, at all stages of decisionmaking in time (1 - project, 2 - planned operation,3 - operational management of the facility), it is extremely important to determine the parameters of the system and its constituent technical elements (regulatory network, conducting network of canals, regulating hydraulic structures, pumping stations, etc.) correctly (objectively). It is they, who largely determine the cost of the system, its economic and environmental efficiency. In turn, this will increase the requirements for the quality of assessment, forecasting and optimization of management of water and general natural reclamation regimes of drained lands, as a prerequisite for solving this problem $[3,4]$.

General conceptual approaches to the optimization of the reclamation regime based on the formulation of general principles and the definition of indicators, criteria and the creation of optimization models are considered in the recommendations [5,6].

The optimization approach has been very successfully applied to determine the parameters of RS and their operating modes [5-11]. As the most promising, they adopted an economic and mathematical method that combines the advantages of traditional hydromechanical and empirical methods, based on the implementation of a complex of forecast and optimization calculations.

But the optimization methods and models developed at that time were considered and used mainly to substantiate local single solutions for individual elements of the system or water regulation technologies, in particular, the optimal parameters of the main canal, hydraulic structures, drainage, etc. [11].

At the same time, it turned out that in the modern conditions of the transition to market relations in the country, this method, as a simplified optimization method, in the form in which it was implemented, considered only the economic component of optimization and does not take into account environmental efficiency when determining the optimal technical and technological solutions and their parameters, that does not correspond to modern requirements [4].

In this regard, there is a need to search for new approaches, methods and models based on the further development of the general optimization theory for its application to substantiate the optimal type, design and parameters of DS and its constituent technical 
elements on ecological and economic principles, taking into account changes in climatic conditions.

\section{Materials and methods}

Research methods are based on the application of systems theory with the basics of systems analysis and modeling in the development of modern approaches to the system optimization of technical, technological and constructive solutions for the creation and operation of drainage systems on ecological and economic principles. At the same time, the systematic approach includes: consideration of the drainage system is not like a technical one, but like a complex natural-technical system; research of their elements, patterns of functioning and development; decomposition of complex goals and objectives of a predominantly hierarchical nature inherent in such systems; application of the methodology of the descending hierarchy of analysis and the ascending hierarchy of synthesis in the development of forecast-optimization models and methods of their implementation.

This is the most modern methodological basis, with the complex of optimization and forecasting-simulation models developed by us, scientific-methodological and information support for their implementation in the structure of the corresponding BIM technologies [12] are used to further improve scientific and methodological approaches to the design and operation of water management and reclamation facilities based on a multivariate assessment of the overall technical, technological, economic and environmental efficiency in accordance with changing conditions.

\section{Results and discussion}

In the development of these approaches, we [3] presented that such a system as part of an agricultural production system (APS) and hydro-reclamation systems (HRS) should be considered as a complex natural and technical, ecological and economic system (CNTEES). A necessary condition is to find a general (global) optimum in such a system only on the basis of the application of system optimization, the essence of which is the sequential determination of local (intermediate) optima for all its main components of heterogeneous elements (in the subsystem effect - mode - technology - design) in their relation. At the same time, for the current level of development of water management, reclamation and agricultural science, system optimization to substantiate optimal design decisions regarding the type, design and parameters of the HRS and its constituent technical elements is carried out at the existing (certain or specified) level of economic (crop yield) and ecological efficiency of functioning of the investigated object.

The solution of such a problem requires, first of all, the development of a model of the system that allows for any element or level of its functioning to consistently determine the optimal total ecological and economic effect created from the action and interaction of interconnected heterogeneous components of the system as a whole with the environment.

The optimal total (integral) ecological and economic effect, which corresponds to the optimal level of technical, technological, economic and ecological efficiency of the DS and is created during its functioning in time $(\tau)$ and space $(f)$, in the general case can be determined by a model of the form

$$
Y^{o}=\int_{0}^{T_{n p}} \int_{0}^{F_{S}} y_{i}^{o}\left(T_{i}, F_{i}\right) d \tau d f, \quad i=\overline{1, n_{i}},
$$

where $Y^{o}$ - is the optimal integrated ecological and economic effect created by the 
functioning of the system in accordance with the current requirements; $y_{i}^{0}$ - parameters of the optimal overall ecological and economic effect created from the action and interaction of interconnected heterogeneous components of the DS elements with the environment; $T_{i}$, $T_{n p}$ - respectively, the project periods of functioning for the $i$-th heterogeneous elements and the system as a whole; $F_{i}, F_{s}$ - respectively, the area for the $i$-th heterogeneous elements and the system as a whole.

In its turn,

$$
y_{i}^{0}=f_{1}^{*}\left(f_{2}^{*}\left(f_{3}^{*}\left(z_{i}\right)\right)\right), i=\overline{1, n_{i}},
$$

where $f_{1}^{*}$ - is the function of optimizing the parameters of the natural reclamation regime $\theta R_{i}, i=\overline{1, n_{i}}$ within the system; $f_{2}{ }^{*}$ - the function of optimizing the parameters of water regulation technologies $\theta S_{i}, i=\overline{1, n_{i}}$ on the system; $f_{3}{ }^{*}$ - the function of optimizing the parameters of design solutions for the system and its technical elements $\theta K_{i}, i=\overline{1, n_{i}}$, ensuring the implementation of appropriate technologies for water regulation on drained land.

The search for the optimal parameters of the components of a complex function (2) and, first of all, the parameters of the modes and associated technological solutions regarding the technologies of water regulation and technical solutions by the type, design and parameters of the system, as well as the constituent technical elements that provide them, depending on the created the general ecological and economic effect, can formally be implemented sequentially through the corresponding inverse functions:

- $\quad$ regarding the optimal parameters of water regulation modes $z_{2}^{0}$,

$$
z_{2}^{0}=f_{1}^{*}-1\left(\hat{y}_{i}\right), \quad i=\overline{1, n_{i}}
$$

- $\quad$ regarding the optimal parameters of technologies $z_{3}^{0}$,

$$
z_{3}^{0}=f_{2}^{*}-1\left(f_{1}^{*}-1\left(\hat{y}_{i}\right)\right), \quad i=\overline{1, n_{i}} ;
$$

- regarding the optimal design parameters $z_{4}^{0}$,

$$
z_{4}^{0}=f_{3}^{*}-1\left(f_{2}^{*}-1\left(f_{1}^{*}-1\left(\hat{y}_{i}\right)\right)\right), \quad i=\overline{1, n_{i}},
$$

where $\hat{y}_{i}$ - the given or adopted parameters of the overall ecological and economic effect for the corresponding heterogeneous elements of the system.

To implement the optimization functions (2) - (5), it is necessary to use the results of the research of the regularities of interconnected processes of water movement both in the main constituent elements of subsystems and in the system as a whole, as well as existing approaches to solving optimization problems in CNTEES.

In this formulation, models (1) and (2) in a general implicit form make it possible, at least theoretically, to substantiate the possibility of setting optimization problems and to determine the optimal parameters of operating, technological and design solutions consistently for all heterogeneous constituent elements in their interconnection and the 
system as a whole at least at the empirical or empirical-functional level of determining the relation between them.

Based on the results of the considered prerequisites and the performed theoretical analysis on the system optimization of technological and design solutions in CNTEES, which includes DS, the management optimization model underlying the implementation of the optimization approach based on the economic and mathematical method in general form is represented as $[3,13]$

$$
Z_{i}^{0}=\underset{\left\{m_{i}\right\}}{\operatorname{extr}}\left(Z_{m_{i}}\right), m_{i}=\overline{1, n_{m_{i}}}, i=\overline{1, n_{i}}
$$

where $Z_{i}^{0}$ - the extreme values according to the accepted conditions of the selected optimality criteria, corresponding to multiple optimal technical and technological solutions for a set of dissimilar elements $\{i\}, i=\overline{1, n_{i}}$ and the system as a whole; $Z_{m_{i}}$ - the values of the optimality criteria for a set of possible alternative options for the implementation of the i-th element within the system $\left\{m_{i}\right\}, m_{i}=\overline{1, n_{m_{i}}}, i=\overline{1, n_{i}}$.

On the basis of the considered approaches, we have improved methods and models of optimization to substantiate the optimal type, design and parameters of DS on ecological and economic principles, taking into account climate change for the short and long term by: 1) changing the established practice of considering the concepts of reclamation objects; 2 ) determining the presence in such a system of a structural connection between the parameters of its heterogeneous elements; 3) the development of principles for the construction and implementation of an integrated model of system optimization of regime, technological and design solutions for water regulation on drained lands: it includes a model of economic optimization, built on the basis of the traditional economic and mathematical approach, and its ecological component, as a limitation, determines the ecological acceptability of the optimal economic solution; 4) substantiation of the criteria for economic and environmental optimization for different levels of management decisionmaking over time; 5) development of a complex of predictive and simulation models for predictive assessment on a long-term basis of variable conditions calculated for heat and moisture supply of growing periods: the corresponding sets of schematized meteorological regimes, water regime and water regulation technologies, productivity (yield) of crops grown.

In turn, the transition to optimization methods determines the need to change the design technology for water management and reclamation facilities based on the use of a multivariate approach, modern information and computer technologies. The practical implementation of a complex of predictive-simulation and optimization calculations in projects for new construction, reconstruction and modernization of DS based on the scientific, methodological, information and software developed by us can be applied with the use of appropriate tools, which is CAD and modern BIM technologies $[4,12]$.

On their basis, a number of optimization and forecasting tasks for water regulation of drained lands were solved, including in the Polesie zone of Ukraine:

1) in projects for the construction and reconstruction of drainage systems:

- substantiation of the choice of possible ways to regulate the water regime and the corresponding types and structures of HRS on drained lands;

- optimization of the parameters of the control network;

- optimization of the estimated supply and parameters of main canals and regulated water receivers;

2) in projects for the operation of drying and moisturizing systems: 
- complex automation of planned water regulation of drained lands; - development of systemic plans for water regulation on a long-term basis;

- creation of informational and advisory systems for operational planning of water regulation;

- implementation of planned water regulation in production conditions;

A characteristic feature of the implementation of system optimization in projects for the creation and operation of DS is a kind of research based on a computer experiment with the widespread use of modern computer and information technologies.

As an example, we consider the application of system optimization, based on improved design technologies [12] when justifying the type, design and parameters of DS, as well as its basic technical elements, in the project of their reconstruction on the drained lands of the "Rassvet" farm of the Rokytnovskiy district of the Rivne region in the Polesie zone of Ukraine.

The soil of the researched area with a total area of 410 hectares are represented by sodmedium-podzolic gley-sandy soil on sands with a filtration coefficient $\left(k_{f}=1,2 \mathrm{~m} /\right.$ day) and share participation in the $\operatorname{system}_{\left(f_{g_{m}}=0,1\right)}$, soddy-gley sandy loam soil $\left(k_{f}=1,0 \mathrm{~m} /\right.$ day $\left., \quad f_{g_{m}}=0,3\right)$ and medium-thick medium-decomposed peatlands $\left(k_{f}=0,4 \mathrm{~m} /\right.$ day $\left., f_{g_{m}}=0,6\right)$. The crop rotation on the array is represented by: oats with equity participation $\left(f_{k}=0,12\right)$, perennial grasses $\left(f_{k}=0,25\right)$, winter wheat $\left(f_{k}=0,12\right)$, corn for silage $\left(f_{k}=0,13\right)$, potatoes $\left(f_{k}=0,13\right)$.

Table 1 presents a comparative characteristic of the main indicators and their parameters, established by traditional methods and approaches in a real project, as well as by improved methods using system optimization in the reconstruction project of this facility.

Table 1. Comparative characteristics of the main indicators and their parameters established by traditional and advanced methods and approaches

\begin{tabular}{|c|c|c|c|}
\hline \multirow[t]{2}{*}{ № } & \multirow{2}{*}{$\begin{array}{l}\text { Key indicators and } \\
\text { parameters }\end{array}$} & \multicolumn{2}{|c|}{ Using: } \\
\hline & & $\begin{array}{l}\text { Traditional methods and } \\
\text { approaches in a real project }\end{array}$ & $\begin{array}{l}\text { Improved methods based on system } \\
\text { optimization in a renovation object } \\
\text { project }\end{array}$ \\
\hline 1. & $\begin{array}{l}\text { Regulating } \\
\text { network }\end{array}$ & $\begin{array}{l}\text { Open network of canals with } \\
\text { a distance between them } B_{r}= \\
60 \mathrm{~m} \text {, calculated module of } \\
\text { drainage flow } q_{r}=0,5 \mathrm{l} / \mathrm{s} \cdot \mathrm{ha}\end{array}$ & $\begin{array}{l}\text { Closed systematic drainage with a } \\
\text { distance between drains } B_{r}=20 \mathrm{~m} \text {, } \\
\text { optimal drainage flow module } q_{r}^{0} \\
=0,6 \mathrm{l} / \mathrm{s} \cdot h a\end{array}$ \\
\hline 2. & $\begin{array}{l}\text { Conducting and } \\
\text { protective network } \\
\text { of open canals, } \\
\text { hydraulic } \\
\text { structures } \\
\text { (gateways } \\
\text { regulators) }\end{array}$ & Structurally & Structurally \\
\hline 3. & $\begin{array}{l}\text { Main canal (main } \\
\text { collector and its } \\
\text { branches) - water } \\
\text { intake }\end{array}$ & $\begin{array}{l}\text { Estimated provision of } \\
\text { sowing consumption is } 10 \% \text {, } \\
Q_{10 \%}=0.73 \mathrm{~m}^{3} / \mathrm{s} \text {; estimated } \\
\text { parameters of the main } \\
\text { collector and its branches: } \\
\text { width along the bottom } b=2 \\
\text { m; slope placement } \\
\text { coefficient } m=2 ; \text { channel }\end{array}$ & $\begin{array}{l}\text { The optimal estimated provision of } \\
\text { the design flow rate is } 15 \%, Q_{15 \%}= \\
0.505 \mathrm{~m}^{3} / \mathrm{s} \text {; optimal parameters of } \\
\text { the main collector and its branches: } \\
\quad b=1.5 \quad \mathrm{~m} \text {; } m=2 \text {; } \\
H=1.5 \mathrm{~m} \text {; }\end{array}$ \\
\hline
\end{tabular}




\begin{tabular}{|c|c|c|c|}
\hline \multirow[t]{2}{*}{ № } & \multirow{2}{*}{$\begin{array}{l}\text { Key indicators and } \\
\text { parameters }\end{array}$} & \multicolumn{2}{|c|}{ Using: } \\
\hline & & $\begin{array}{l}\text { Traditional methods and } \\
\text { approaches in a real project }\end{array}$ & $\begin{array}{l}\text { Improved methods based on system } \\
\text { optimization in a renovation object } \\
\text { project }\end{array}$ \\
\hline & & depth $H=2 \mathrm{~m}$; & \\
\hline 4. & $\begin{array}{l}\text { Type, construction } \\
\text { of DS }\end{array}$ & Draining & Draining with preventive locking \\
\hline 5. & $\begin{array}{l}\text { Economic } \\
\text { efficiency }\end{array}$ & $\begin{array}{l}\text { Land use ratio } K_{3}=0,88 ; \\
\text { payback period } T_{0}=10 \text { years }\end{array}$ & $\begin{array}{l}\text { Land use ratio } K_{3}=0,96 ; \\
\text { discounted payback period } \\
\hat{T}_{0}=7 \text { years }\end{array}$ \\
\hline 6. & $\begin{array}{l}\text { Environmental } \\
\text { efficiency }\end{array}$ & Not determined & $\begin{array}{l}\text { Acceptable (permissible) - relative } \\
\text { to the formation of the average } \\
\text { module of drainage flow in the } \\
\text { system, which is permissible } \\
\text { according to environmental } \\
\text { requirements, } q_{s}=0.421 / \mathrm{s} \cdot \mathrm{ha} \text {, } \\
\text { which is less than } \hat{q}_{\text {екол }}=0.46 \mathrm{l} / \mathrm{s} \\
\text { ha; quite reliable - relative to the } \\
\text { coefficient of environmental } \\
\text { reliability of the project, } k_{H}=0.54 \text {, } \\
\text { should be in the range of values } \\
\left.0,5<k_{H} \leq 1,0\right) \text {. }\end{array}$ \\
\hline
\end{tabular}

The note. Preventive locking - regulation of a part of the flow within the drainage system during the recession of the spring flood.

\section{Conclusions}

Thus, new approaches are considered and proposed, they are based on the application of system optimization to substantiate on ecological and economic principles the type, design and parameters of drainage systems and their constituent technical elements in projects of new construction, reconstruction and modernization in accordance with recent changing conditions.

\section{References}

1. P. Kovalenko, A. Rokochinskiy, J. Jeznach, P.Volk, R. Koptyuk, N. Prykhodko. Evaluation of climate change in Polissie region and ways of adaptation to it. Journal of Water and Land Development, 41(1), 72-82 (2019)

2. B.B. Shumakov. Melioration in the twenty-first century. Reclamation and Water Management, 4-6 (1996)

3. P. Kovalenko, A. Rokochinskiy, Yu. Mazhayskiy, P. Volk, L. Volk, O. Chernikova. Construction and agricultural drainage parameter optimization considering economic and environmental requirements. Engineering for Rural Development. Jelgava, 10091017 (2020) DOI: 10.22616 / ERDev.2020.19.TF237

4. Y.A. Mazhaiskiy, A.N. Rokochinskiy, A.A.Volchek, O.P. Meshik, E. Eznakh. Environmental management of Polesie. Ryazan: Meshcher. Branch of All-Russian Research Institute of Hydrotechnics and Melioration Named after A.N. Kostyakova, 902 (2017) 
5. I.P. Aydarov, A.I. Golovanov, Y.N. Nikolskiy. Optimization of meliorative regimes of irrigated and drained agricultural land. Moscow: Agrometeoizdat, 60 (1990)

6. L.M. Rex. System research of meliorative processes and systems. Moscow: Aslan, 192 (1995)

7. L.A. Downey. Water-Yield relations fornonforage crops. J.Irrig. Drainage Div.- ASCE, 98(IR1), 107-115 (1972)

8. K.T. Khomik. Basics of calculating drainage systems. Bureau of Scientific and Technical Information of the Ministry of Agriculture of the Estonian SSR, 280 (1985)

9. I.V. Minaev. Design principles of drainage and drainage-humidification systems with optimal parameters. Water Industry of Belarus, 3-18 (1977)

10. M.O. Lazarchuk, A.V. Cherenkov, A.M. Rokochinskiy. Optimization of drainage systems calculation and management. Monograph, Rivne- NUWREM, 354 (2009)

11. A.P. Likhatsevich. Land reclamation of Belarus. Minsk: BelNIIMiL, 308 (2001)

12. A. Rokochinskiy, N. Frolenkova, J. Jeznach, R. Koptiuk, V.Turcheniuk, P.Volk. Reclamation projects development improvement technology considering optimization of drained lands water regulation based on BIM. Przegląd Naukowy Inżynieria i Kształtowanie Środowiska, 432-443 (2019) DOI:10.22630/PNIKS.2019.28.3.40 